Tersedia online di: http://ejournal-balitbang.kkp.go.id/index.php/jra

\title{
PERFORMA PEMIJAHAN IKAN TUNA SIRIP KUNING, Thunnus albacares DI KERAMBA JARING APUNG
}

\author{
Jhon Harianto Hutapea, Ananto Setiadi, Gunawan, dan I Gusti Ngurah Permana
}

Balai Besar Riset Budidaya Laut dan Penyuluhan Perikanan

(Naskah diterima: 21 Maret 2016; Revisi final: 21 Maret 2017; Disetujui publikasi: 21 Maret 2017)

\begin{abstract}
ABSTRAK
Ikan tuna sirip kuning merupakan komoditas ekspor yang bernilai ekonomis tinggi yang populasinya semakin menurun di alam. Penelitian ini dilaksanakan di Balai Besar Penelitian dan Pengembangan Budidaya Laut, Gondol dan bertujuan untuk mengetahui performa pemijahan ikan tuna sirip kuning yang dipelihara di dalam keramba jaring apung. Sebanyak 100 ekor induk ikan tuna dengan ukuran bobot sekitar 15-30 kg dipelihara dalam keramba sejak tahun 2014. Induk ikan diberi pakan berupa ikan layang dan cumi-cumi dengan rasio 2:1 dua kali sehari (pagi dan sore hari). Pengamatan yang dilakukan meliputi tingkah laku induk, pemijahan, dan keragaan telur yang dihasilkan, serta kualitas air terutama suhu dan oksigen dilakukan setiap hari. Induk ikan memijah untuk pertama kalinya terjadi pada tahun 2015. Selanjutnya pemijahan terjadi hampir setiap malam hari dengan jumlah telur yang dapat dikumpulkan berkisar 30.000-3.600.000 butir. Daya tetas telur yang diperoleh berkisar $26 \% 96 \%$ dengan ketahanan hidup larva tanpa pakan (survival activity index-SAI) berkisar 0,1-3,8. Berdasarkan hasil pengamatan ini dapat disimpulkan bahwa induk ikan tuna sirip kuning umur dua tahun dapat memijah di keramba jaring apung dan menghasilkan performa pemijahan yang baik.
\end{abstract}

\section{KATA KUNCl: ikan tuna sirip kuning; keramba jaring apung; performa pemijahan}

ABSTRACT: Spawning performance of yellowfin tuna, Thunnus albacares reared in floating net cage. By: Jhon Harianto Hutapea, Ananto Setiadi, Gunawan, and I Gusti Ngurah Permana

Yellowfin tuna is an export commodity and high economic value but its population tend to decrease. The research was conducted at Institute for Mariculture Research and Development of Indonesia. The purpose of this study was to observe the spawning performance of yellowfin tuna in floating net cage. The study was started in 2014 using 100 broodstock with estimated weight range of $15-30 \mathrm{~kg}$. Feed supplied for broodstock were scad mackerel and squid with 2:1 ratio and was given twice a day in the morning and afternoon. The observations included broodstock behavior, spawning, egg performance, and daily morning of water quality (temperatureand dissolve oxygen). First spawning was observed in January, 2015, where eggs were found in floating net collector deployed in floating net cage. Spawning occured nearly every day at night time. The number of eggs collected was ranged from 30,000 to 3,600,000 eggs with varied hatching of $26 \% 96 \%$ and survival activity index of $0.1-3.8$. Based on these results, it can be concluded that yellowfin tuna broodstock can spawn in floating net cage near shore at the age of two year with good spawning performance.

\section{KEYWORDS: floating net cage; yellowfin tuna; spawning performance}

\section{PENDAHULUAN}

Data statistik FAO menunjukkan bahwa kontribusi hasil penangkapan ikan tuna sirip kuning (Thunnus albacares) terhadap total tonase perdagangan dunia mencapai 27\% (Anonymous, 2014) dan Indonesia

\footnotetext{
\# Korespondensi: Balai Besar Riset Budidaya Laut dan Penyuluhan Perikanan. JI. Br. Gondol, Kec. Gerokgak Kab. Buleleng, Kotak Pos 140, Singaraja, Bali 81101, Indonesia. Tel. + (0362) 92278

E-mail: hutapeaharianto@gmail.com
}

berkontribusi sebanyak 12\%yaitu sebanyak 1,1 juta ton (Jusuf, 2014).

Mengacu pada kondisi perikanan Bluefin tuna di tahun 1960 yang produksinya mencapai 80.000 ton dan di tahun 2012 turun menjadi kurang dari 10.000 ton (Kennedy, 2014), bukan tidak mungkin kondisi yang sama akan terjadi pada ikan tuna sirip kuning sehingga diperlukan untuk melakukan usaha budidaya. Usaha budidaya ikan tuna saat ini masih mengandalkan benih alam yang berupa baby tuna hasil tangkapan 
nelayan. Hal ini tentunya juga akan mempercepat terjadinya penurunan populasinya di alam (De Stefano $\&$ Van Der Heijden, 2007).

Balai Besar Penelitian dan Pengembangan Budidaya Laut (BBPPBL), Gondol-Bali telah berpengalaman dalam transportasi ikan tuna hidup dan pemeliharaan hingga pemijahan induk ikan tuna dalam bak beton (Hutapea et al., 2010). Namun selama pemeliharaan induk dalam bak beton ditemukan beberapa permasalahan seperti tingginya mortalitas induk akibat ikan menabrak dinding, pemijahan hampir setiap hari sehingga ketika ada infeksi endoparasit dalam telur, siklus endoparasit tersebut tidak bisa diputus maka seluruh telur yang dihasilkan pada hari selanjutnya tidak dapat digunakan dan produktivitas induk pada tahun ketiga pemijahan sangat rendah. Untuk menanggulangi permasalahan tersebut maka sejak tahun 2013, pemeliharaan induk ikan tuna mulai dialihkan dalam karamba jaring apung (KJA) di laut (Hutapea et al., 2015).

Informasi yang tersedia menyatakan bahwa ikan tuna sirip kuning betina memijah untuk pertama kalinya pada umur 1,6-2,0 tahun (Mergulies et al., 2007). Penelitian lain menggunakan panjang cagak sebagai standar dan diperoleh informasi bahwa ikan tuna betina memijah untuk pertama kalinya pada ukuran panjang cagak 52,5-56,7 cm di perairan Filipina, yang berbeda dengan di Samudera Pasifik Tengah bagian khatulistiwa pada panjang cagak $70-80 \mathrm{~cm}$, bahkan di Samudera Hindia umumnya pada panjang cagak di atas $90 \mathrm{~cm}$ (Sumadhiharga, 2009). Hasil penelitian Ashida \& Horie (2015) menemukan bahwa suhu perairan merupakan faktor yang sangat berpengaruh terhadap pemijahan ikan tuna. Ikan tuna sirip kuning T. albacares di Panama mulai memijah ketika suhu air mencapai sekitar $23,3^{\circ} \mathrm{C}-29,7^{\circ} \mathrm{C}$ (Mergulies et al., 2007). Sebaliknya, di daerah khatulistiwa dengan posisi lintang $10^{\circ} \mathrm{LU}-15^{\circ} \mathrm{LU}$ dan bujur $120^{\circ} \mathrm{BT}-180^{\circ} \mathrm{BT}$ di Samudera Pasifik, ikan tuna sirip kuning dapat memijah sepanjang tahun dengan puncak pemijahan pada bulan Juli-November. Induk ikan tuna sirip kuning dengan ukuran bobot lebih dari $9 \mathrm{~kg}$ atau panjang cagak lebih dari 82,2 cm; dengan perkiraan umur sekitar dua tahun yang dipelihara dalam bak terkontrol dapat memijah sepanjang tahun (Hutapea et al., 2010).

Memperhatikan beberapa faktor yang memengaruhi pematangan dan pemijahan ikan tuna sirip kuning baik berdasarkan ukuran, umur, maupun lokasi pemijahannya, maka perlu dilakukan penelitian untuk mengetahui performa pemijahan induk ikan tuna sirip kuning yang dipelihara dalam keramba jaring apung (KJA) di laut.

\section{BAHAN DAN METODE}

\section{Pemeliharaan Induk Ikan Tuna}

Pemeliharaan induk ikan tuna sirip kuning dilakukan di KJA milik BBPPBL yang terletak di Dusun Gondol Desa Penyabangan Kecamatan Gerokgak Kabupaten Buleleng, Bali. KJA berbentuk bundar dengan diameter $50 \mathrm{~m}$ dan kedalaman jaring $8 \mathrm{~m}$ dengan menggunakan jaring dengan bahan High Density Poly Ethylene (HDPE) dengan mata jarring 3,5 inci; yang dipasang berjarak 300-400 m dari pantai dengan kedalaman perairan 20-30 m.

Calon induk ikan tuna dengan bobot $0,3-0,4 \mathrm{~kg}$ ditangkap di sekitar rumpon yang terletak 12-15 neuticalmile lepas pantai Utara Bali pada pertengahan tahun 2013 dengan mengikuti metode penangkapan dan transportasi ke KJA yang telah dikembangkan sebelumnya (Hutapea et al., 2010). Pemeliharaan ikan dilakukan hingga mencapai induk dengan memberikan pakan dan observasi kesehatan ikan sesuai dengan metode yang dikembangkan Hutapea et al. (2010).

Pakan yang diberikan selama pemeliharaan adalah pakan segar berupa ikan layang dan cumi-cumi dengan perbandingan 2:1. Persentase pemberian sebanyak 3\% $5 \%$ dari estimasi biomassa ikan tuna yang dipelihara per hari sehingga diperoleh tingkat kekenyangan induk yang optimum dan pemberian pakan ditingkatkan sampai $7 \%$ per hari terutama pada musim ikan liar yang melimpah. Pemberian pakan dilakukan pada pagi dan sore hari. Stok pakan segar disimpan dalam ruangan pendingin (cold storage) dengan suhu minus $20^{\circ} \mathrm{C}-30^{\circ} \mathrm{C}$. Pakan dipindahkan ke dalam ruang dingin (chiller) dengan suhu $0^{\circ} \mathrm{C}-5^{\circ} \mathrm{C}$ sehari sebelum diberikan pada induk ikan agar es pada pakan meleleh dan mudah dibersihkan. Jumlah pakan segar yang diberikan disesuaikan setiap 2-3 hari. Jika pemanfaatan pakan oleh induk ikan tuna meningkat, maka pemberian jumlah pakan juga ditingkatkan. Demikian juga sebaliknya jumlah pakan diturunkan jika nafsu makan ikan berkurang. Penambahan vitamin juga dilakukan sebagai immunostimulant agent yaitu Vitamin $\mathrm{C}$ dan $\mathrm{E}$, serta vitamin mix dengan jumlah $1 \%$ dari estimasi bobot kering pakan segar yang diberikan. Vitamin dimasukkan ke dalam kapsul (0,3 g vitamin/kapsul) Ialu kapsul ini disisipkan ke dalam ikan layang dan cumicumi sebelum diberikan ke induk ikan.

\section{Pemijahan Induk dan Penanganan Telur Ikan Tuna}

Pengamatan pemijahan induk ikan tuna dilakukan setiap malam selama seminggu setelah terlihat adanya tanda-tanda pemijahan, antara lain induk ikan berenang 
beriringan dengan kecepatan yang lebih tinggi dari biasanya. Untuk mengetahui adanya pemijahan, air lapisan permukaan dalam KJA disaring dengan menggunakan saringan seser bertangkai (scope net) dengan ukuran mata jaring $400 \mu \mathrm{m}$, dan hasilnya dimasukkan ke dalam gelas beaker untuk diamati ada tidaknya telur. Proses pengamatan, pemanenan, dan penanganan telur ikan tuna disajikan pada Gambar 1.

Jika ditemukan telur, maka pengambilan telor dilakukan secara manual dengan menggunakan serok mengitari KJA atau dengan menggunakan sampan kecil (katamaran) bermesin yang di bagian depannya dilengkapi dengan seser. Agar telur tidak keluar dari KJA sebelum dipanen, pada sore hari berikutnya dilakukan pemasangan jaring mengelilingi bagian dalam KJA dengan lebar jaring $2 \mathrm{~m}$ dan mata jaring 500-600 $\mu \mathrm{m}$. Jaring dipasang $50 \mathrm{~cm}$ di atas air hingga $1,5 \mathrm{~m}$ di bawah permukaan air. Agar jaring tetap dalam posisi yang baik, maka bagian atasnya diikat ke jaring KJA sementara bagian bawahnya dipasang pemberat.

Hasil pemanenan telur yang terkumpul dalam serok atau seser, disaring dengan saringan bertingkat berukuran mesh size $1.000 \mu \mathrm{m}$. Telur ikan tuna dapat melewati saringan tersebut, sedangkan partikel sampah dan organisme hidup lainnya yang berukuran lebih dari $1.000 \mu \mathrm{m}$ tidak lolos. Selanjutnya, telur ikan tuna disaring lagi dengan saringan ukuran mesh size $400 \mu \mathrm{m}$, agar sampah dan organisme hidup yang halus terbuang dan diperoleh telur yang lebih bersih. Hasil saringan ini dimasukkan ke dalam bak penampungan berupa ember plastik volume $15 \mathrm{~L}$ yang telah dilengkapi dengan aerasi. Setelah panen selesai, telurtelur dalam ember ditransportasikan ke darat dan dimasukkan dalam bak fiber kerucut volume $100 \mathrm{~L}$ untuk dilakukan pemisahan antara telur dan organisme lain (copepod) yang masih tercampur dengan telur. Metode pemisahan memanfaatkan sifat photaksis positif copepod sedangkan telur dengan performa yang baik akan mengapung di permukaan air. Untuk itu, bak fiber yang telah berisi telur ditutup kain hitam dari bagian atas hingga dasar, tanpa aerasi dan pada bagian dasar bak diberi cahaya (lampu senter). Telur yang baik akan mengapung ke lapisan permukaan sementara copepod dan organisme lainnya mendekati cahaya dan telur rusak berkumpul di dasar bak. Setelah organisme target terkumpul, air bagian dasar bak dibuang dengan cara membuka keran secara perlahanlahan sampai semua telur yang rusak, copepod, dan organisme lain terbuang. Selanjutnya telur disucihamakan melalui perendaman dalam larutan formalin $25 \mathrm{mg} / \mathrm{L}$ selama 10 menit dengan tetap diaerasi dengan kecepatan yang cukup untuk mengaduk telur secara merata. Sekitar 100 butir telur diambil secara acak untuk keperluan pengamatan dan pengukuran diameter telur dan butiran minyak, stadia perkembangan embrio, dan kondisi telur (steril atau fertile), serta ada tidaknya infeksi endoparasit. Pengamatan dilakukan di bawah mikroskop Nikon SMZ1000 dan Nikon EclipseE600 yang dihubungkan dengan kamera Nikon Digital DXM1200F-TV Lens C-0.6X Japan dan komputer yang dilengkapi program Win ROOF v 5.0 untuk penyimpanan gambar dan program ACT-Minati Corporation untuk pengukuran.

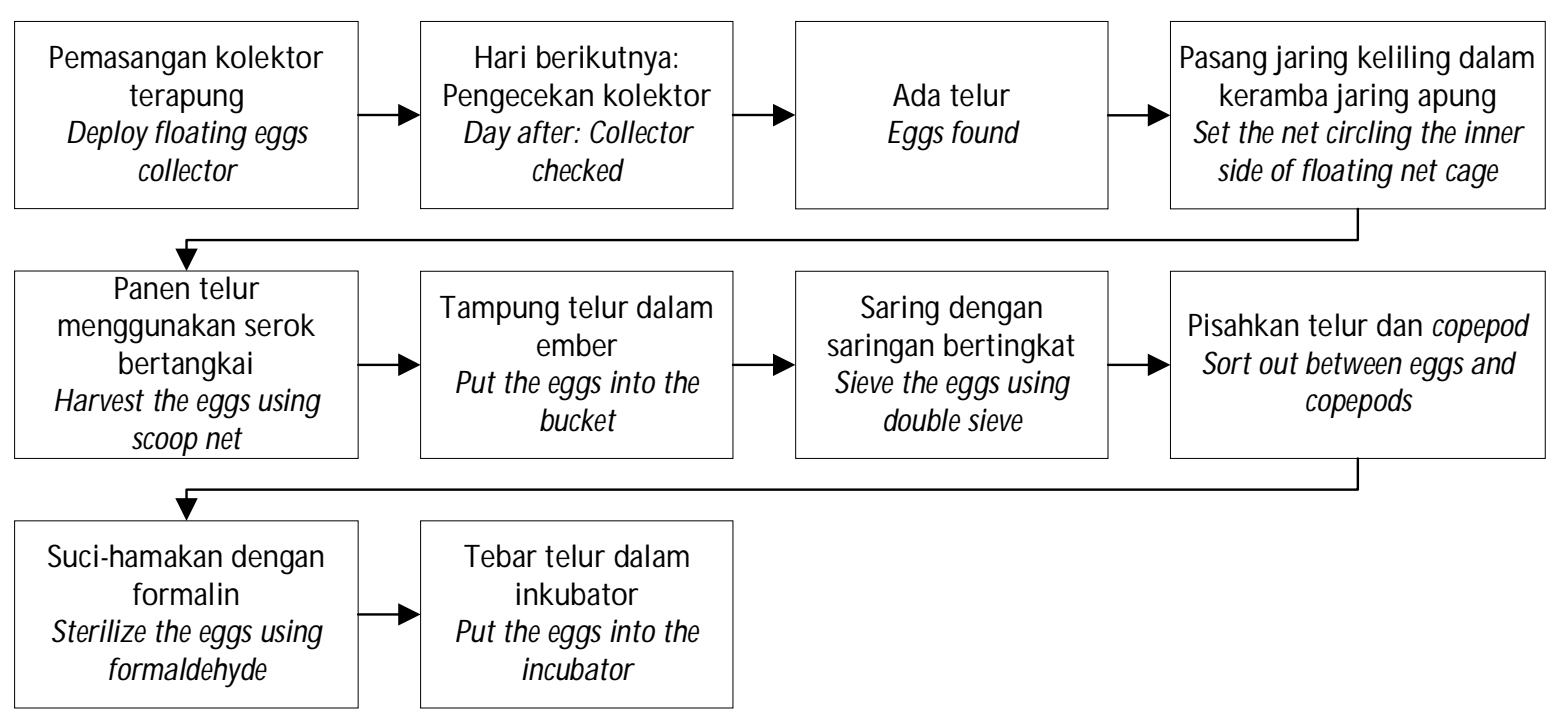

Gambar 1. Skema pengamatan pemijahan induk ikan tuna sirip kuning (Thunnus albacares), pemanenan dan penanganan telur

Figure 1. Schematic on spawning observation of yellowfin tuna (Thunnus albacares), harvesting and handling of eggs 
Setelah suci-hama selesai, telur disaring dengan saringan bermata jaring $600 \mu \mathrm{m}$, dibilas, lalu dimasukkan ke dalam bak inkubasi berupa bak fiber glass kerucut bervolume $200 \mathrm{~L}$. Bak dilengkapi dengan sistem aerasi dan air laut mengalir kontinu $(600 \mathrm{~mL}$ ) det.). Penghitungan jumlah telur dilakukan secara sampling, dengan mengambil $100 \mathrm{~mL}$ air penampungan telur secara acak sebanyak tiga kali. Jumlah telur dalam setiap sampel dihitung lalu dikonversi ke dalam volume bak untuk memperoleh jumlah telur ikan tuna dalam bak inkubasi.

Parameter yang diamati meliputi frekuensi pemijahan, jumlah telur, dan kualitas telur yang meliputi diameter telur, rasio butir minyak, dan diameter telur, jumlah butiran minyak, dan analisis keaktifan larva (SAI). Untuk menentukan SAI, air berisi telur dari bak inkubator diambil dengan menggunakan gelas beaker $100 \mathrm{~mL}$, lalu dengan menggunakan pipet gelas $5 \mathrm{~mL}$, telur dipilih dan dihitung untuk dimasukkan dalam beaker $1 \mathrm{~L}$ yang telah berisi air laut bersih hingga mencapai jumlah 100 butir dan kemudian gelas beaker tersebut ditempatkan dalam bak yang berfungsi sebagai water bath. Setelah telur menetas, dilakukan penghitungan telur yang tidak menetas dan larva yang mati. Setiap hari berikutnya dilakukan penghitungan larva yang mati dan demikian seterusnya hingga semua larva mati. Data yang diperoleh ditampilkan dalam bentuk gambar dan tabel yang selanjutnya dianalisis secara deskriptif.

\section{HASIL DAN BAHASAN}

Berdasarkan pengamatan harian pada saat pemberian pakan, pemberian pakan sebesar 3\%5\%dari biomassa induk, yaitu 35-60 kg pakan yang diberikan, hanya dalam waktu 1-2 menit sudah habis dimakan oleh induk ikan tuna. Hasil pengamatan sebelumnya pada pemeliharaaan induk tuna dalam bak beton dan diberi pakan hingga kenyang menunjukkan penurunan tingkat pemangsaan setelah tiga menit pemberian pakan (Hutapea et al., 2010) sebagai tanda induk sudah kenyang.

Ikan tuna sebagai ikan perenang cepat dengan jumlah kebutuhan pakan yang tinggi akan berusaha menangkap ikan liar, yaitu ikan lain yang ada di dalam maupun di luar KJA, jika pakan yang diberikan tidak mencukupi. Hal ini dapat menyebabkan induk ikan tuna menabrak jaring dan bahkan dapat menyebabkan kematian induk. Oleh karena itu, pemberian pakan ditingkatkan dari 3\%5\%biomassa per hari menjadi 7\% per hari (85-102 kg/hari) terutama pada musim di mana ikan liar di sekitar KJA melimpah. Dengan cara ini diharapkan dapat mengurangi agresivitas induk dan juga dapat menstimulasi kematangan gonad dan pemijahan.
Pemijahan induk ikan tuna di KJA pertama kali diamati pada Januari 2015 dengan estimasi umur induk 2-3 tahun dan bobot badan $20-30 \mathrm{~kg}$. Performa pemijahan induk di KJA selama tahun 2015 dapat dilihat pada Gambar 2. Tidak ada perbedaaan estimasi umur induk pertama kali memijah antara induk yang dipelihara dalam bak beton maupun dalam KJA, tetapi berbeda dalam estimasi ukurannya (Hutapea et al., 2010) karena pertumbuhan ikan tuna dalam KJA jauh lebih cepat dibandingkan dengan yang dipelihara dalam bak beton.

SelamaJanuari hingga Maret 2015 jumlah telur yang dihasilkan masih sedikit. Hal ini dapat terjadi karena persentasi jumlah induk yang baru pertama kali memijah masih sedikit (Masuma, 2006). Laju pematangan gonad dan pemijahan induk dalam kolam atau jaring lebih rendah dibandingkan di alam bebas (Seoka et al., 2008). Jika dihubungkan dengan kualitas air, kemungkinan ada hubungan linier positif antara jumlah telur yang dihasilkan dengan suhu dan kandungan oksigen. Ketika oksigen terendah pada bulan April yaitu sekitar 3,6 mg/L dan suhu permukaan air terendah terjadi pada bulan Juni yaitu $27,0^{\circ} \mathrm{C}$ (Sutarmat et al., 2015), produksi telur ikan tuna lebih rendah dibandingkan dengan produksi telur di bulan Agustus.

Pada bulan Januari hingga Maret, pengukuran kualitas air dilakukan di sekitar KJA dan mulai bulan April, pengukuran dilakukan oleh bagian penelitian kualitas air di perairan sekitar Gondol, seperti tertera pada Tabel 1. Selanjutnya data kualitas air yang digunakan adalah data sekunder dari penelitian Sutarmat et al. (2015) yang melakukan pengamatan kualitas air di perairan pantai Gondol, termasuk di sekitar KJA ikan tuna sirip kuning. Ketika kandungan oksigen meningkat dan mencapai tertinggi (> 5,0 $\mathrm{mg} / \mathrm{L}$ ) pada bulan Agustus dan suhu air juga meningkat mencapai tertinggi pada bulan September-November sebesar $29,5^{\circ} \mathrm{C}$ (Sutarmat et al., 2015) produksi telurtelur ikan tuna juga berada pada puncaknya.

Setelah diyakini induk memasuki musim pemijahan, dilakukan pemasangan jaring kolektor telur yang menempel pada bagian dalam dari jaring pemeliharaan induk ikan. Dalam hal ini digunakan jaring kolektor telur berwarna hitam karena lebih efektif dibandingkan dengan yang berwarna putih. Warna putih diduga terlalu kontras sehingga menghambat induk ikan tuna untuk memijah ke permukaan. Di samping pemasangan jaring kolektor telur keliling KJA, juga dilakukan pemasangan jaring kolektor di tengah KJA. Jaring ini dapat bergerak mengikuti arah arus dan berguna sebagai kolektor terapung. Pengamatan pemijahan tetap dilakukan dengan cara mengambil air 


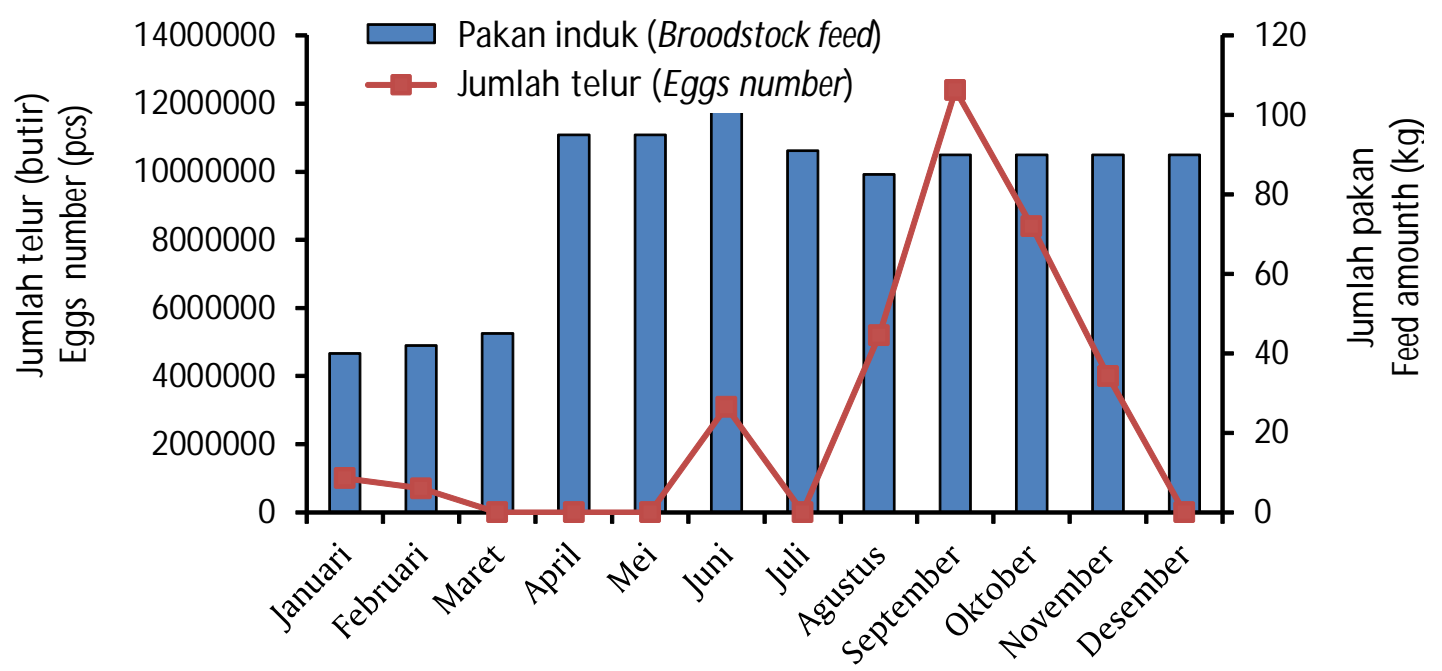

Waktu pemeliharaan (bulan)

Rearing period (months)

Gambar 2. Jumlah telur yang dihasilkan dan jumlah pakan yang diberikan dalam pemeliharaan induk ikan tuna sirip kuning (Thunnus albacares) di KJA selama tahun 2015

Figure 2. Number of eggs produced and feed given in the rearing of yellowfin tuna (Thunnus albacares) broodstock in floating net cage in year 2015

dan mengecek ada tidaknya telur. Telur yang dipanen hanyalah telur yang sudah dibuahi, yaitu telur yang mengapung di lapisan permukaan air. Pemanenan telur dilakukan selama 1-3 jam, tergantung jumlah telur yang telah diperoleh. Diperkirakan hanya sebagian kecil dari telur yang dipijahkan yang dapat dipanen karena luasnya permukaan KJA, serta keterbatasan alat dan waktu. Telur ditampung dalam ember selama 1-2 jam dengan jumlah antara 100.000-4.000.000 butir. Hasil penelitian Andamari et al. (2012) menunjukkan bahwa induk ikan tuna sirip kuning di alam dengan bobot badan antara $46,2-71,5 \mathrm{~kg}$ mempunyai fekunditas antara 2,7-6,7 juta butir atau sekitar 58.000-93.000 butir/kg induk. Berdasarkan informasi fekunditas ini maka diperkirakan bahwa jumlah telur yang dihasilkan per pemijahan mungkin jauh lebih banyak dari jumlah yang dapat dipanen. Total telur yang diproduksi juga tidak dapat diestimasi karena pemanenan telur tidak dilakukan setiap malam dan lama pemanenan yang tidak konsisten. Ketika jumlah telur yang dipanen sudah banyak walaupun waktunya hanya sebentar, telur harus segera ditransportasikan agar tetap terjaga kualitasnya. Oleh karena itu, ke depan agar dapat melakukan estimasi produksi telur per hari, harus ditetapkan periode pemanenan dan lama waktu pemanenan yang tetap.

Frekuensi pemijahan induk ikan tuna dalam KJA dapat dilihat dari hasil pengecekan telur pada kolektor terapung. Hasil pengecekan ini menunjukkan bahwa induk ikan tuna memijah hampir setiap malam. Secara umum diketahui bahwa masa pemijahan ikan tuna

Tabel 1. Parameter kualitas air di dalam keramba jaring apung pemeliharaan induk ikan tuna sirip kuning (Thunnus albacares) tahun 2015

Table 1. Water quality parameters in floating net cage of yellowfin tuna (Thunnus albacares) broodstock rearing in year 2015

\begin{tabular}{lccc}
\hline \multirow{2}{*}{$\begin{array}{c}\text { Bulan } \\
\text { Months }\end{array}$} & \multicolumn{3}{c}{ Nilai kisaran Nalue range) } \\
\cline { 2 - 4 } & $\begin{array}{c}\text { Suhu } \\
\text { Temperature ('C) }\end{array}$ & $\begin{array}{c}\text { Salinitas } \\
\text { Salinity (ppt) }\end{array}$ & $\begin{array}{c}\text { Oksigen terlarut } \\
\text { Disolved oxygen (mg/L }\end{array}$ (\%) \\
\hline Januari & $28,7-30,4$ & $31-33$ & $5,4-8,7(85 \% 116 \%)$ \\
Februari & $28,5-31,6$ & $33-34$ & $7,2-9,5(93 \% 132 \%)$ \\
Maret (March) & $27,9-31,1$ & $33-34$ & $6,6-9,2(86 \% 124 \%)$ \\
\hline
\end{tabular}


dapat berlanjut terus selama ketersediaan pakan memadai. Hal ini terbukti dari hasil penelitian Hutapea et al. (2010) bahwa ikan tuna sirip kuning dapat memijah sepanjang tahun selama ketersediaan pakan kontinu.

Jumlah telur yang diproduksi tidak menunjukkan adanya korelasi dengan fase bulan, seperti juga dilaporkan Mergulies et al. (2007). Namun ada hal lain yang menarik yang ditemukan oleh Gordoa et al. (2009), bahwa induk ikan tuna sirip biru (Thunnus thynnus) yang sedang ditarik dari daerah penangkapan ke daerah tempat pemeliharaan (penggemukan), memijah, dan bertepatan dengan munculnya larva uburubur. Hal ini juga penting diamati mengingat pada saat ubur-ubur melimpah di sekitar KJA ikan tuna, juga ditemukan jumlah telur induk ikan tuna sirip kuning yang banyak. Diduga ubur ubur sebagai pemicu pemijahan atau sebenarnya berhubungan dengan kesuburan perairan sehingga ketersediaan pakan alami melimpah dan ini menjadi trigger bagi induk-induk ikan laut pada umumnya untuk melakukan pemijahan.

Ukuran diameter telur dan butiran minyaknya disajikan pada Gambar 3. Jumlah telur yang dapat dipanen pada bulan M aret-Mei sangat sedikit sehingga tidak dilakukan pengukuran. Tidak ada perbedaan ukuran diameter telur yang nyata pada setiap bulan walaupun terlihat bahwa pada bulan November dan
Desember telur cenderung lebih kecil dibandingkan bulan-bulan lainnya, di daerah sub tropis ukuran telur sangat dipengaruhi oleh suhu perairan, di mana semakin tinggi suhu air pada saat pemijahan maka diameter telur akan lebih kecil (Masuma, 2009). Ternyata ukuran diameter telur ikan tuna sirip biru relatif lebih besar yaitu sekitar $1 \mathrm{~mm}$ dengan butiran minyak $250 \mu$ m atau dengan rasio 25\% (Mylonas et al., 2007). Sementara hasil penelitian pada ikan tuna sirip kuning ini menunjukkan rasio antara butiran minyak dengan diameter telur hanya $18 \% 21 \%$

Telur dan larva ikan tuna sirip kuning hasil pemijahan di KJA dari setiap pemanenan telur selalu dilakukan uji untuk mengetahui daya tetas dan ketahanan larva tanpa diberi pakan (survival activity index-SAI) ditampilkan pada Tabel 2.

Ketahanan hidup larva ikan tuna sirip kuning tanpa pakan dalam penelitian ini rata-rata empat hari dengan nilai SAI 0,12 hingga 3,88 dengan rata-rata tertinggi pada bulan Agustus yaitu 2,58 $\pm 1,20$. Larva dengan nilai SAl yang tinggi menunjukkan sintasan yang secara nyata lebih tinggi dibandingkan dengan larva dengan SAl yang rendah (Matsuo et al., 2006). Nilai SAI tidak hanya berhubungan dengan penyimpanan nutrien tetapi juga berhubungan dengan kondisi lingkungan (Wang et al., 2013). Ketika lingkungan hidup dalam kondisi optimal, maka energi lebih banyak yang dapat

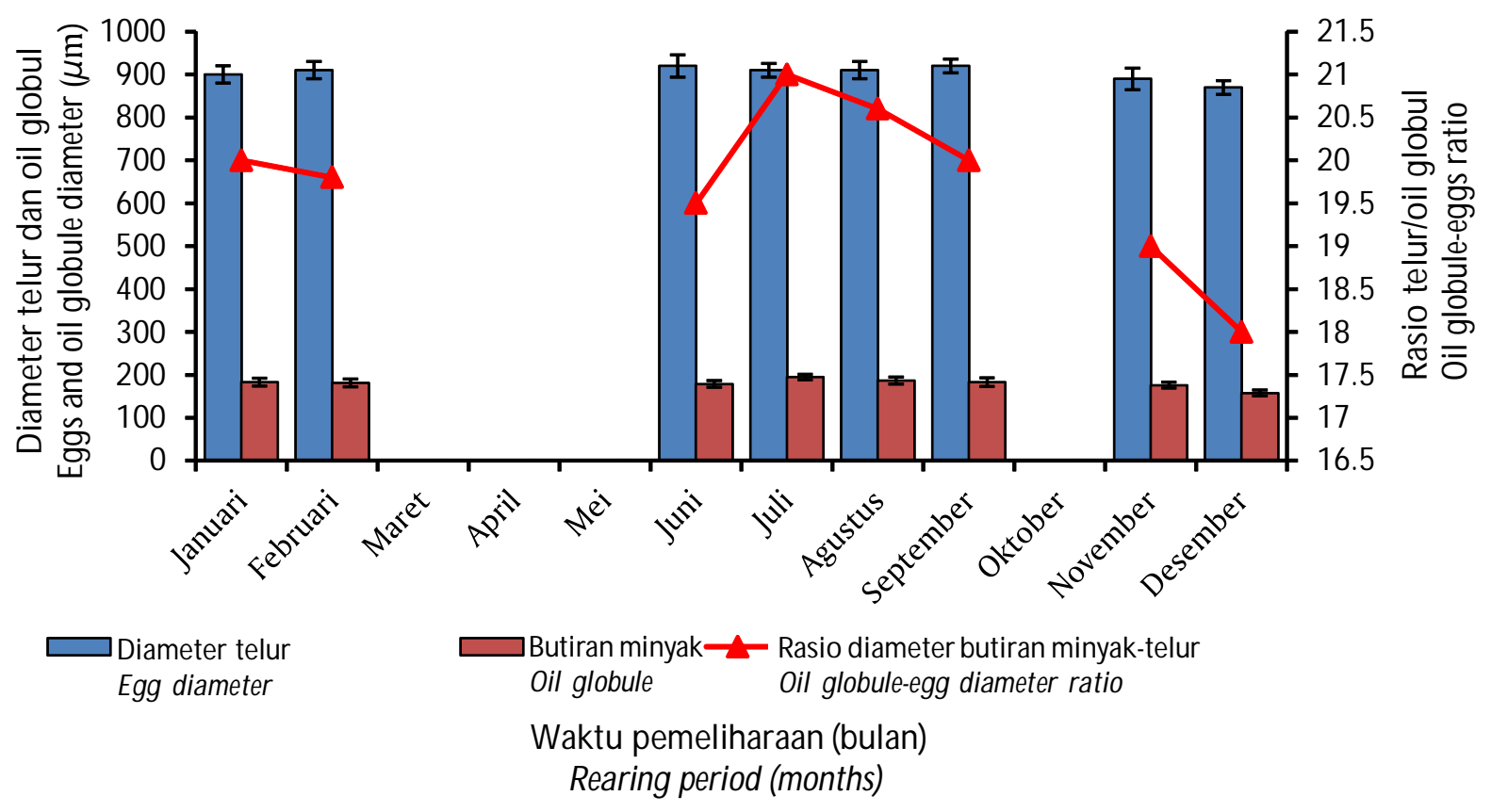

Gambar 3. Diameter telur, diameter butiran minyak dan rasio butiran minyak, dan diameter telur ikan tuna sirip kuning, Thunnus albacares hasil pemijahan di KJA selama tahun 2015

Figure 3. Egg diameter, oil globule diameter and its ratio of yellowfin tuna, Thunnus albacares from broodstock spawned in floating net cage during year 2015 
Tabel 2. Frekuensi pemanenan telur ikan tuna sirip kuning (Thunnus albacares) per bulan, rata-rata ketahanan hidup larva, dan indeks ketahanan hidup larva sepanjang tahun 2015

Table 2. Fequencies of yellowfin tuna (Thunnus albacares) eggs harvested per month, mean larval survival (day after hatch), mean and standard deviation of survival activity index (SAI) of larvae in year 2015

\begin{tabular}{|c|c|c|c|c|}
\hline \multirow{2}{*}{$\begin{array}{l}\text { Bulan } \\
\text { Months }\end{array}$} & \multirow{2}{*}{$\begin{array}{c}\text { Jumlah pemanenan } \\
\text { telur } \\
\text { Frequency of eggs } \\
\text { harvesting }\end{array}$} & \multirow{2}{*}{$\begin{array}{l}\text { Rata-rata ketahanan } \\
\text { hi dup larva (hari) } \\
\text { Mean larval } \\
\text { survival (days) }\end{array}$} & \multicolumn{2}{|c|}{$\begin{array}{l}\text { Nilai indeks ketahanan hidup larva } \\
\text { Survival activity index of larvae }\end{array}$} \\
\hline & & & $\begin{array}{l}\text { Kisaran } \\
\text { Range }\end{array}$ & $\begin{array}{c}\text { Rata-rata } \pm \text { Standar deviasi } \\
\text { Mean } \pm \text { Standard deviation }\end{array}$ \\
\hline $\begin{array}{l}\text { Januari } \\
\text { January }\end{array}$ & 6 & 4.0 & $1.20-3.22$ & $2.18 \pm 0.69$ \\
\hline $\begin{array}{l}\text { Februari } \\
\text { February }\end{array}$ & 8 & 3.75 & $1.35-2.67$ & $1.76 \pm 0.41$ \\
\hline $\begin{array}{l}\text { Maret } \\
\text { March }\end{array}$ & 10 & 4.0 & $1.46-3.52$ & $2.07 \pm 0.71$ \\
\hline $\begin{array}{l}\text { April } \\
\text { April }\end{array}$ & 15 & 3.7 & $1.03-3.26$ & $1.84 \pm 0.76$ \\
\hline Mei (May) & 3 & 4.0 & $0.78-2.40$ & $1.57 \pm 0.82$ \\
\hline Juni (June) & 4 & 4.0 & $1.19-2.31$ & $1.93 \pm 0.46$ \\
\hline Juli (July) & 3 & 4.0 & $1.07-3.71$ & $2.23 \pm 1.11$ \\
\hline $\begin{array}{l}\text { Agustus } \\
\text { August }\end{array}$ & 11 & 4.5 & $0.84-3.88$ & $2.58 \pm 1.20$ \\
\hline $\begin{array}{l}\text { September } \\
\text { September }\end{array}$ & 6 & 4.0 & $0.12-3.13$ & $1.90 \pm 1.02$ \\
\hline $\begin{array}{l}\text { Oktober } \\
\text { October }\end{array}$ & 10 & 4.0 & $0.74-3.00$ & $1.87 \pm 0.68$ \\
\hline $\begin{array}{l}\text { November } \\
\text { November }\end{array}$ & 6 & 5.0 & $0.68-3.44$ & $2.29 \pm 0.96$ \\
\hline $\begin{array}{l}\text { Desember } \\
\text { Descember }\end{array}$ & No data & -- & -- & -- \\
\hline
\end{tabular}

digunakan untuk perkembangan dan pertumbuhan larva. Interaksi antara suhu dan salinitas yang optimal juga dapat meningkatkan nilai SAI pada larva ikan tuna sirip kuning (Kim et al., 2015). Dengan demikian dapat dikatakan bahwa kualitas telur yang dihasilkan dalam penelitian ini sudah baik dan mampu memproduksi larva, serta diharapkan dapat memproduksi benih ikan tuna sirip kuning.

\section{KESIMPULAN}

Induk ikan tuna sirip kuning yang dipelihara di KJA menunjukkan performa reproduksi yang baik. Frekuensi pemijahan terjadi hampir setiap hari, dengan estimasi jumlah telur yang dapat dipanen antara 30.000-3.600.000 butir/pemijahan dengan ukuran diameter telur $870-920 \mu \mathrm{m}$. Kualitas telur yang dihasilkan berupa daya tetas bervariasi antara $26 \%$ 96\% larva maksimal bertahan hidup tanpa diberi pakan hingga lima hari setelah menetas dengan nilai indeks ketahanan larva (Survival Activity Index) kualifikasi baik antara 0,1-3,8.

\section{UCAPAN TERIMA KASIH}

Penelitian ini dilaksanakan atas dana APBN T.A. 2015 yang dalam pelaksanaannya dibantu oleh teknisi. Penulis mengucapkan terima kasih kepada Putu Sudarsana, Jafar Shodiq, Syahrodi, dan Muhammad Arif yang telah membantu penelitian ini.

\section{DAFTAR ACUAN}

Andamari, R., Hutapea, J.H., \& Prisantoso, B.I. (2012). Aspek reproduksi ikan tuna sirip kuning (Thunnus albacares). Jurnal Ilmu dan Teknologi Kelautan Tropis, 4(1), 89-96.

Anonymous. (2014). Review of the statistical data and fishery trends for tropical tunas. Indian Ocean Tuna Commission (IOTC). Fifteen Working Party 
on Tropical Tunas, San Sebastian, Spain, 23-28 October 2013, 71 pp.

Ashida , H., \& Horie, M. (2015). Reproductive condition, spawning season, batch fecundity and spawning fraction of skipjack tuna Katsuwonus pelamis caught around Amami-Oshima, Kagoshima, Japan. Fisheries Science, 81(5), 861-869.

De Stefano, V., \& Van Der Heijden, P.G.M. (2007). Bluefin tuna fishing and ranching: a difficult management problem. New Medit, 6(2), 59-64.

Gordoa, A., Olivar, M.P., Arevalo, R., Viñas, J., Molí, B., \& Illas, X. (2009). Determination of Atlantic bluefin tuna (Thunnus thynnus) spawning time within a transport cage in the western Mediterranean - ICES. Journal of Marine Science, 66, 22052210.

Hutapea, J.H., Setiadi, A., Gunawan, \& Permana, G.N. (2010). Perbaikan teknik penanganan calon induk ikan tuna sirip kuning (Thunnus albacares) pasca penangkapan dan dalam bak pengo batan. Prosiding Forum Inovasi Teknologi Akuakultur 2010. Teknologi Akuakultur. Bidang Budidaya Laut. Pusat Penelitian dan Pengembangan Perikanan. Jakarta, Buku 1, hlm. 359-365.

Hutapea, J.H., Setiadi, A., Gunawan, \& Permana, I G.N. (2015). Teknologi pembesaran dan pemijahan ikan tuna sirip kuning di Keramba Jaring Apung. Prosiding Forum Inovasi Teknologi Akuakultur 2015. Pusat Penelitian dan Pengembangan Perikanan. Jakarta, hlm. 1065-1072.

Jusuf, G. (2014). Position and roles of Indonesia tuna fisheries globally: Challenges and breakthrough to the development of tuna fisheries management plan. Directorate General of Capture Fisheries, Ministry of Marine Affairs and Fisheries. Indonesia, Bali Tuna Conference, 19-21 November 2014.

Kennedy, R. (2014). Regional review of tuna fisheries-the need for effective implementation of the conservation and management measures for Southern Bluefin Tuna. Commission for the Conservation of Southern Bluefin Tuna. Bali Tuna Conference, 19-21 November 2014.

Kim, Y-S., Delgado, D.I., Cano, I.A., \& Sawada, Y. (2015). Effect of temperature and salinity on hatching and larval survival of yellowfin tuna Thunnus albacares. Fisheries Science, 81(5), 891-897.
Masuma, S. (2006). A review of broodstock management and larviculture of the Pacific northern bluefin tuna in Japan. LarvaeFish and Shellfish Larviculture Symphosium. Ghent-Belgium, 13 pp.

Masuma, S. (2009). Biology of Pacific Bluefin tuna inferred from approaches in captivity. Collect. Vol. Sci. Pap. ICCAT, 63, 2007-229.

Matsuo, Y., Kasahara, Y., Hagiwara, A., Sakakura, Y., \& Arakawa, T. (2006). Evaluation of larval quality of viviparous scorpion fish, Sebastiscus marmoratus. Fisheries Science, 72(5), 948-954.

Mergulies, D., Suter, J.M., Hunt, S.L., Olson, R.J., Scholey, V.P., Wexler J.B., \& Nakazawa, A. (2007). Spawning and early development of captive yellowfin tuna (Thunnus albacares). Fish. Bull., 105, 249-265.

Mylonas, C.C., Bridges, C., Gordin, H., Ríos, A.B., García, A., De La Gándara, F., Fauvel, C., Suquet, M., Medina, A., Papadaki, M., Heinisch, G., De Metrio, G., Corriero, A., Vassallo-Agius, R., Guzmán, J.M., Mañanos, E., \& Zohar, Y. (2007). Preparation and administration of gonadotropinrealising hormone agonist ( $\mathrm{GnRHa}$ ) implants for the artificial control of reproductive maturation in captive-reared Atlantic bluefin tuna (Thunnus thynnus thynnus). Rev. Fish. Sci., 15, 183-210.

Seoka, M., Kurata, M., Tamagawa, R., \& Kumai, H. (2008). Dietary supplementation of salmon roe phospholipid enhances the growth and survival of Pacific bluefin tuna Thunnus orientalis larvae and juveniles. Aquaculture, 275(1-4), 225-234.

Sumadhiharga, O.K. (2009). Ikan Tuna. Pusat Penelitian Oseanografi, Lembaga IImu Pengetahuan Indonesia. Jakarta, $129 \mathrm{hlm}$.

Sutarmat, T., Permana, I G.N., Astuti, P.A., Jamaris, Z., Slamet, B., \& Ismi, S. (2015). Analisis kualitas perairan Gondol dan Teluk Pegametan berdasarkan status indeks trofik. Laporan Teknis. Balai Besar Penelitian dan Pengembangan Budidaya Laut. Gondol, $24 \mathrm{hlm}$.

Wang, Y., Cui, L., Li, G., \& Lu, W. (2013). Ontogenis from embryo to juvenile and salinity tolerance of Japanese devil stinger Inimicus japonicus during early life stage. Diunduh, dalam www. ncbi. nlm. nih.gov/pmc/articles/PMC3706744/ pada 06 September 2016. Springerplus, 2, 289. 